Artigo

\title{
Validade de construto e confiabilidade: uma escala para a satisfação discente
}

\author{
Construct validity and reliability: a scale for student satisfaction
}

Validez del constructo y fiabilidad: una escala para la satisfacción del alumno

\author{
Vanussa Braga Rezende Dutra ${ }^{1}$ \\ [0000-0002-9356-4280] \\ Viviane Leite Dias de Mattos ${ }^{2}$ \\ [0000-0002-3512-6290]
}

\begin{abstract}
Resumo
Este estudo apresenta a etapa de validação de construto de um instrumento desenvolvido com a finalidade de mensurar o nível de satisfação dos discentes de cursos de graduação em Matemática. A amostra foi composta por 142 discentes de duas instituições de ensino superior localizadas no extremo sul do Brasil. Depois de uma Análise Exploratória de Dados e avaliação de sua fatorabilidade, a identificação e extração de fatores foi feita por meio de uma Análise de Componentes Principais e uma Análise Fatorial Exploratória com o Método dos Eixos Principais, aplicadas à pontuação atribuída à importância de cada item. Também foi realizada uma análise de confiabilidade por meio do coeficiente Alfa de Cronbach. A análise permitiu identificar quatro fatores, denominados de "Recursos materiais e humanos", "Professor", "Metodologia" e "Disciplinas", que por meio de 19 itens conseguiram explicar $68,98 \%$ da variância.
\end{abstract}

Palavras-chave: Qualidade. Satisfação discente. Graduação em Matemática. Análise Fatorial.

\begin{abstract}
This study is about validation of construct of an instrument made to measure the level of satisfaction of students of undergraduate courses in Mathematics. This study involved 142 students from two educational institutions. After the exploratory data analysis, the identification and extraction of factors being done by through a Principal Component Analysis and an Exploratory Factor Analysis with the Main Axes Method, applied to the score attributed to the importance of each item. A reliability analysis was also performed using the Cronbach's Alpha Coefficient. The analysis made it possible to identify four factors, called "Material and human resources", "Teacher", "Methodology" and "Disciplines", which through 19 items managed to explain $68.98 \%$ of the variance.
\end{abstract}

Keywords: Quality. Student satisfaction. Undergraduate in Mathematics. Factor Analysis.

\section{Resumen}

Este estudio presenta la etapa de validación de constructo de un instrumento desarrollado para medir el nivel de satisfacción de los estudiantes de cursos de pregrado en Matemáticas. La muestra consistió en 142 estudiantes de dos instituciones de educación superior ubicadas en el extremo sur de Brasil.

${ }^{1}$ nussadutra@gmail.com, Mestre, Discente, Universidade Federal do Rio Grande, Rio Grande/Rio Grande do Sul/Brasil.

2 viviane.leite.mattos@gmail.com, Doutora, Docente, Universidade Federal do Rio Grande, Cidade/Estado/País. 
Después de un análisis de datos exploratorios y una evaluación de su capacidad de factorización, la identificación y extracción de factores se realizó a través de un análisis de componentes principales y un análisis de factores exploratorios con el método de los ejes principales, aplicado a la puntuación atribuida a la importancia de cada elemento. . También se realizó un análisis de confiabilidad utilizando el coeficiente alfa de Cronbach. El análisis permitió identificar cuatro factores, llamados "Recursos materiales y humanos", "Profesor", "Metodología" y "Disciplinas", que a través de 19 ítems lograron explicar el $68.98 \%$ de la varianza.

Palabras claves: Calidad. Satisfacción estudiantil. Graduación en Matemáticas. Análisis factorial.

\section{Introdução}

De acordo com El-Hilali, Al-Jaber e Hussein (2015), o nível educacional da população de um país é o principal fator desencadeante do seu desenvolvimento econômico, sendo considerado um dos pilares do seu desenvolvimento. No Brasil, vários estudos apontam para o fato de que a educação no Ensino Básico tem sido um problema, apresentando baixos índices de rendimento escolar, o que se repete no Ensino Superior. Em cursos de Engenharia, Física e Matemática, por exemplo, a reprovação e evasão escolar costumam ser bastante elevadas nos semestres iniciais. A existência deste problema de aprendizagem é evidenciada por Cruz e Silva (2019), que cometam a constante preocupação dos educadores na área da Matemática em buscar meios para facilitar o seu aprendizado.

Vários estudos já foram desenvolvidos com o objetivo de identificar as possíveis causas do fracasso neste processo de ensino-aprendizagem. Rodriguez, Meneguethi e Poffal (2015), por exemplo, estudaram sua relação com o perfil dos discentes de um curso de Matemática, identificando que as dificuldades de aprendizagem durante esta graduação ocorrem principalmente devido a falhas na educação do Ensino Médio.

Entretanto, para Schleich, Polydoro e Santos (2006), ao ingressar em um curso de graduação, os discentes criam uma expectativa que, se não atendida, pode resultar em desempenho mais baixo, dificuldade de integração, insucesso e evasão. Para estes autores, o fracasso no processo ensino-aprendizagem está mais relacionado ao atendimento das expectativas dos discentes, o que evidencia a necessidade de um ensino adequado as suas demandas. Esses autores ainda chamam a atenção para o fato de que no Brasil, nas duas últimas décadas, foram abertas muitas vagas em cursos de graduação, o que dificulta a adequação das políticas educacionais à diversidade de características e de expectativas desta grande população discente.

Observe que, no Brasil, em 2018, foram oferecidas mais de 13,5 milhões de vagas em cursos de graduação, sendo $72,9 \%$ vagas novas e $26,9 \%$ vagas remanescentes (INEP, 2019), o que caracteriza um cenário gigantesco. Soma-se o fato de que o ensino tradicional parece não estar conseguindo atender as demandas dos discentes em função das recentes transformações sociais, entre as quais, o desenvolvimento tecnológico e a popularização dos meios de comunicação e informação (OLIVEIRA, 2019).

Cruz e Silva (2019) mostram a importância do uso dos recursos didáticos e metodológicos no ensino da Matemática, entre os quais os jogos matemáticos, que notadamente colaboram com a motivação discente e, consequentemente, com a sua satisfação. Nesse sentido, Rozal, Santo e Chaves (2015) avaliaram a percepção, observação e interpretação de discentes em relação a uma atividade interdisciplinar envolvendo o conhecimento matemático, constatando que este envolvimento propiciou a sua motivação, e 
consequentemente sua satisfação, fazendo com que a prática fosse considerada um sucesso em termos de aprendizagem.

Contemplar as expectativas dos discentes, propiciando sua satisfação, pode estar diretamente relacionado com o sucesso do processo de ensino-aprendizagem. Quando a qualidade percebida pelo estudante supera sua expectativa em relação ao ambiente acadêmico, ele se sente satisfeito e, por consequência, se torna mais motivado para obter um melhor desempenho acadêmico. Parte-se da premissa de que o conhecimento da satisfação discente permite a implementação de ações que podem contribuir para melhorar os índices de rendimento e evasão escolar.

Cunha, Gomes e Beck (2016) consideram que a satisfação é um fator fundamental para a manutenção de alunos em cursos de graduação, bem como para obter uma imagem positiva da instituição de ensino. De acordo com Lodi et al (2019), a avaliação da satisfação discente, assim como a implementação de atividades na instituição de ensino que a propiciem, é um procedimento crucial para evitar a evasão escolar e todos os demais fatores associados ao desligamento de estudantes. Esses autores também citaram diversos autores que mostraram a importância da satisfação discente para o desempenho acadêmico, o engajamento do estudante no processo de ensino- aprendizagem e o progresso acadêmico, o que acontece em todos os níveis educacionais, dos anos iniciais ao ensino superior.

Além disso, Cock e Halvari (2001) evidenciaram que a motivação para alcançar o sucesso está positivamente correlacionada com o desempenho e a satisfação na escola. Já para Davis e Swanson (2001), discentes que experimentam falhas nas atividades desenvolvidas em sala de aula ficam insatisfeitos e demonstram forte propensão a compartilhar as informações negativas sobre suas experiências, agindo como multiplicadores de informações negativas.

Considerando que a satisfação discente pode ser encarada como um feedback da qualidade do processo de ensino aprendizagem, obter uma escala para mensurá-la pode ser de grande valia para um gestor que almeje a qualidade deste processo. Sultan e Wong (2013), por exemplo, afirmam que as instituições de ensino superior estão cada vez mais preocupadas em avançar no propósito de se tornarem competitivas, por meio da valorização de seus atributos, principalmente no que diz respeito à qualidade de seus cursos e de sua infraestrutura, necessitando realizar um trabalho de excelência na definição de estratégias para a realização de suas práticas. Neste contexto, a satisfação dos acadêmicos é de suma importância, pois diversos autores a relacionam ao desempenho acadêmico.

Além disso, para Drucker (1993) apud Souza e Reinert (2010), o aprendizado vitalício deve ser atraente e trazer em si grande satisfação, o que, no entender de Souza e Reinert (2010), vale para qualquer tipo de aprendizado, inclusive aquele que acontece em cursos de graduação.

Dutra, Ávila e Mattos (2017) apresentaram a etapa de validação de conteúdo de um instrumento desenvolvido para mensurar a satisfação dos discentes de cursos de graduação em Matemática, com o objetivo de definir uma amostra de itens relevantes para os diferentes domínios que compõe a satisfação. Este artigo complementa o estudo desenvolvido, apresentando a etapa de validação de construto do referido instrumento, que tem a finalidade de comprovar se o conjunto de itens definido na etapa de validação anterior realmente reflete o construto a ser mensurado: a satisfação.

Esse artigo foi divido em cinco seções. A seção seguinte apresenta uma sínteses dos principais estudos que fundamentaram a construção do instrumento elaborado, enquanto a 
seção 3 informa a metodologia utilizada no processo de análise dos dados. Na seção 4 apresentam-se os resultados encontrados e, na seção 5, as considerações finais.

\section{Estudos relacionados}

Michaelis (2009) define satisfação como uma sensação agradável que os indivíduos sentem quando as coisas ocorrem a sua vontade ou se cumprem a seu contento e, de acordo com Su e Sampaio (2013), sua definição operacional se baseia na confirmação de expectativas. Esta definição permite constatar a subjetividade presente neste constructo e, com isto, a dificuldade em mensurá-lo. Vários estudos, alguns dos quais citados a seguir, já foram desenvolvidos com este objetivo. Na construção dos diversos instrumentos foram utilizados diferentes contextos, com variadas especificidades, que identificaram diferentes itens e dimensões, evidenciando a necessidade de sua constante adaptação à população investigada.

Soares, Vasconcelos e Almeida (2002) desenvolveram um instrumento, denominado Questionário de Satisfação Acadêmica (QSA), para avaliar a satisfação dos discentes em relação a diversos aspectos de sua vida acadêmica. Tratou-se de um questionário de autorelato composto por 13 itens em sua versão inicial, elaborados para avaliar três diferentes áreas: qualidade das relações estabelecidas dentro e fora de contexto universitário; infraestrutura, equipamentos e serviços disponibilizados pela instituição e características do curso que frequentam. No processo de validação de construto, feito por meio de uma Análise Fatorial, o instrumento foi respondido por 938 discentes de 16 cursos da Universidade do Minho/Portugal, de diferentes áreas (Ciências, Engenharias, Ensino e Ciências Sociais e Humanas), sendo utilizada uma escala Likert com cinco níveis. A análise estatística identificou três fatores, que explicaram $51 \%$ da variância. O primeiro avaliou características do curso que o aluno frequentava (resultados acadêmicos, sistema de avaliação, grau de investimento pessoal, organização e interesse do curso e relações com os professores), enquanto o segundo fator avaliou características institucionais. Já o terceiro fator avaliou relações estabelecidas com pessoas significativas, inseridas ou não no contexto universitário. Para os autores a satisfação em relação aos professores, assim como a satisfação em relação aos funcionários, não ficaram inseridas no fator ligado às relações sociais, conforme o esperado. A primeira ficou inserida no fator curso, enquanto que a segunda, no fator instituição. Ainda, a satisfação com a vida acadêmica, associada inicialmente ao fator curso, ficou no fator social, traduzindo uma natureza mais social para o ensino. Eles também evidenciam que, no estudo desenvolvido, o grau de satisfação encontrou-se menos dependente de variáveis de entrada e mais influenciado por variáveis contextuais, concordando com outros estudos já realizados.

Schleich, Polydoro e Santos (2006) também desenvolveram um instrumento com esta mesma finalidade. Eles iniciaram o processo com uma validação de conteúdo dos itens utilizados no instrumento criado por Soares, Vasconcelos e Almeida (2002), adaptado ao contexto brasileiro. Uma revisão de literatura complementou a listagem inicial, gerando a Escala de Satisfação com a Experiência Acadêmica (ESEA), composta por 40 itens. Estes foram avaliados por meio de uma escala Likert com sete níveis e envolveram cinco dimensões: pessoal, interpessoal, carreira, curso e instituição. A validação de constructo foi feita por meio de uma Análise Fatorial e empregou uma amostra de 351 discentes de três cursos noturnos nas áreas de Ciências Sociais Aplicadas (Administração e Comunicação) e Ciências Exatas (Computação) de uma universidade privada de São Paulo. O instrumento foi composto por 35 itens, distribuídos em três dimensões: satisfação com o curso, oportunidade de desenvolvimento e satisfação com a instituição, que explicaram $47,7 \%$ da variância. Os 
autores evidenciaram que os fatores satisfação com o curso e satisfação com a instituição identificam-se com fatores encontrados por Soares, Vasconcelos e Almeida (2002), embora com mais itens e incluindo questões relacionais. Vale salientar que o fator considerado como o mais importante para a satisfação, denominado satisfação com o curso foi composto por 13 itens, dos quais 8 se referiam aos professores. Estes autores ainda evidenciaram a necessidade de desenvolvimento de propostas analisando a satisfação a partir da relação entre as expectativas ou nível de importância atribuída pelo estudante aos diversos aspectos da vida acadêmica, o que está sendo considerado no presente estudo. Na análise desenvolvida, os autores eliminaram quatro itens por apresentarem carga fatorial elevada em mais de um fator, diferentemente do que ocorreu no presente estudo.

Cunha, Gomes e Beck (2016) realizaram um levantamento de dados para que assertivas sobre o ambiente acadêmico, definidas a partir dos fatores propostos por Paswan e Young (2002) - Student Instructional Rating System, SIRS -, fossem avaliadas por 257 acadêmicos de cursos de Ciências Contábeis de três instituições de ensino localizadas em Santa Catarina. Eles buscavam avaliar o impacto de cinco fatores: envolvimento dos professores, interesse do estudante, interação estudante-professor, demandas do curso e organização do curso com a satisfação geral, fator introduzido no instrumento posteriormente por Vieira, Milach e Hupper (2008). As 41 assertivas, agrupadas em seis fatores, foram avaliadas por meio de uma escala Likert, com 7 níveis. Os resultados foram analisados por meio de uma Análise Fatorial Confirmatória, além de Equações Estruturais. Neste estudo, Cunha, Gomes e Beck (2016) concluíram que o envolvimento dos professores e o interesse do estudante tem relação positiva com a sua satisfação geral, concordando com os achados de Vieira, Milach e Hupper (2008), que evidenciaram a importância do envolvimento do professor no processo ensino-aprendizagem.

Bonici e Junior (2011) realizaram uma pesquisa para mensurar o nível de satisfação dos discentes em relação à disciplina online de Probabilidade e Estatística oferecida por uma universidade. A amostra investigada foi composta por 111 discentes de cursos de graduação nas áreas de Administração e Negócios e de Ciências Exatas e Tecnologias. O instrumento foi constituído de 57 assertivas, avaliados por escala Likert com cinco níveis, sendo identificadas as dimensões: características do tutor, características dos discentes, características das tecnologias, suporte das disciplinas e características das disciplinas.

Souza e Reinert (2010) também realizaram uma pesquisa investigativa de caráter exploratório e descritivo sobre a satisfação discente, abrangendo 356 discentes do curso de Administração, nas modalidades presencial e a distância, de uma universidade localizada no estado do Mato Grosso do Sul. Diferentemente dos outros estudos, este trabalhou inicialmente com perguntas abertas para que o estudante pudesse indicar livremente o que considerasse relevante para a sua satisfação em relação ao curso. Foram identificados temas que foram classificados e posteriormente agrupados. Os fatores percebidos como geradores da satisfação foram agrupados em seis categorias: estrutura curricular, corpo docente, ambiente social, infraestrutura, características do curso e aspectos pessoais. Este estudo também se diferencia dos demais no sentido de associar o construto mensurado às necessidades e expectativas dos discentes, o que foi feito no presente estudo.

\section{Material e métodos}

A construção do referido instrumento iniciou com uma busca por estudos já desenvolvidos com a finalidade de mensurar a satisfação, viabilizando a identificação de itens 
e dimensões que possivelmente compõe o construto a ser mensurado. Esta amostra inicial de itens passou por uma validação de conteúdo. Mais detalhes sobre esta etapa podem ser encontrados em Dutra, Ávila e Mattos (2017). Nesta versão resultante, que foi acompanhada de um termo de consentimento livre e esclarecido e de dados de identificação, foi solicitado aos discentes que atribuíssem dois escores a cada um dos itens selecionados: um para a sua importância em relação à satisfação e outro para a qualidade percebida em seu curso de graduação.

Para verificar se o conjunto de itens selecionado na validação de conteúdo realmente refletia a satisfação, o instrumento foi submetido à validação de construto, sendo aplicado a uma amostra de acadêmicos que frequentavam cursos de Matemática. A aplicação foi coletiva, sendo a escolha das turmas realizada conforme a autorização do coordenador do curso e do professor responsável.

Depois de fazer a caracterização da amostra investigada a partir de alguns dados de identificação, realizou-se uma análise exploratória nos dados com o objetivo de conhecer algumas de suas propriedades. Nessa etapa foram utilizadas algumas técnicas analíticas, como cálculo de medidas descritivas e testes de normalidade, além de alguns recursos gráficos.

A análise subsequente foi realizada apenas nos escores atribuídos à importância dos itens para a satisfação. Inicialmente foi utilizada uma Análise de Componentes Principais (PAC) para determinar a quantidade máxima de possíveis fatores a serem considerados na análise, além de avaliar a fatorabilidade dos dados. Na operacionalização desse procedimento, avaliou-se uma matriz de correlações e respectivas significâncias com o objetivo de avaliar o relacionamento entre as variáveis, além do teste de esfericidade de Bartlett, que testa a hipótese nula de que as variáveis não estejam correlacionadas, e do coeficiente $\mathrm{KMO}$, que indoca que os dados podem ser analisados por meio desta técnica se seu resultado for superior a 0,6. Uma análise gráfica por meio do ScreePlot também foi realizada para identificar componentes a serem considerados na análise por apresentarem autovalor pelo menos igual à unidade (critério de Kaiser).

Seguindo, realizou-se uma Análise Fatorial com o Método dos Eixos Principais (PAF) para determinar a quantidade de dimensões que efetivamente foram utilizadas, os itens que as compõe e suas respectivas cargas fatoriais. Para facilitar a identificação dos componentes dos fatores, foram avaliados resultados com a utilização de rotação Varimax e de rotação Oblíqua. Inicialmente a carga fatorial mínima para reter um item dentro de um fator foi 0,32, evoluindo até 0,45, pois de acordo com Pasquali (2005), uma carga fatorial inferior a 0,32 é inaceitável, enquanto que o valor 0,45 já pode ser considerado razoável. Vale salientar que a PAF foi executada várias vezes, sendo eliminados os itens um a um, em função de sua carga fatorial e de sua interpretação. Esta análise, que foi acompanhado de uma análise de confiabilidade executada pelo coeficiente de Cronbach, que avalia a consistência interna de um item, o que possibilitou a elaboração da versão final do instrumento para a população em estudo.

Mais detalhes sobre a fundamentação teórica das diversas técnicas estatísticas utilizadas neste estudo e respectivos critérios para interpretação dos achados podem ser encontrados em Pasquali (2005), Hair et al. (2009) e Tabachnick e Fidel (2012).

Como resultado da aplicação desta metodologia foi obtida a coleção de itens. Salientase que a análise estatística usada na validação de construto foi executada a partir das pontuações atribuídas à importância de cada item. Além disso, diferentemente da muitos dos estudos que embasaram este trabalho, seguiu-se a recomendação de Parasuraman et al. 
(1985), seguida por Souza e Reinert (2010), medindo a satisfação pela diferença entre o valor atribuídos para a qualidade percebida de cada item e a sua importância para a satisfação.

\section{Resultados e discussão}

O instrumento preliminar, composto por 35 declarações, embasou-se principalmente nos estudos desenvolvidos por Cunha, Gomes e Beck (2016), Schleich, Polydoro e Santos (2006) e Soares, Vasconcelos e Almeida (2002), que foram submetidas à validação de conteúdo, sendo ajustadas, transformadas em itens e reduzidas a 27. Mais detalhes sobre esta etapa de validação de conteúdo podem ser encontrados em Dutra, Ávila e Mattos (2017).

Os 27 itens selecionados foram submetidos à validação de constructo que utilizou uma amostra constituída por 142 discentes pertencentes à população acadêmica estudada: estudantes que frequentavam cursos de Matemática Licenciatura ou Matemática Aplicada em duas instituições públicas de ensino superior, localizadas no sul do RS, caracterizado pelas informações apresentadas na Tabela 1 e na Tabela 2.

Tabela 1 - Características sócio-bio-econômicas dos discentes respondentes

\begin{tabular}{llcc}
\hline Variáveis & \multicolumn{1}{c}{ Níveis } & $f$ & $\%$ \\
\hline Gênero & Masculino & 74 & 52,1 \\
& Feminino & 68 & 47,9 \\
\hline Idade (anos) & Menor que 20 & 29 & 20,4 \\
& Entre 20 e 29 & 66 & 46,5 \\
& Entre 30 e 39 & 27 & 18,9 \\
& Maior que 39 & 19 & 13,5 \\
& NI & 1 & 0,7 \\
\hline Estado Civil & Solteiro & 98 & 69,0 \\
& Casado & 37 & 26,1 \\
& Divorciado & 6 & 4,2 \\
& Viúvo & 1 & 0,7 \\
\hline Número de pessoas que compõe a família & Menor que 3 & 40 & 28,0 \\
& Entre 3 e 5 & 87 & 61,0 \\
& Maior que 5 & 14 & 9,9 \\
& NI & 1 & 0,7 \\
\hline Renda Familiar (em sal. mínimos) & Até 1 & 12 & 8,5 \\
& De 1,1 a 3 & 73 & 51,4 \\
& De 3,1 a 7 & 38 & 26,8 \\
& Mais de 7 & 7 & 4,9 \\
& NI & 12 & 8,5 \\
\hline Trabalha & Sim & 58 & 40,8 \\
& Não & 84 & 59,2 \\
\hline Turno de trabalho & Manhã & 7 & 4,9 \\
& Tarde & 5 & 3,5 \\
& Noite & 1 & 0,7 \\
& Manhã e tarde & 40 & 28,2 \\
& Manhã, tarde e noite & 4 & 2,8 \\
& NI & 1 & 0,7 \\
\hline Fon & &
\end{tabular}

Fonte: levantamento de dados.

Obs: $f$ representa frequência de ocorrência; NI representa não informou. 
Conforme Tabela 1, a maioria dos discentes respondentes eram do sexo masculino (52,1\%), solteiros (69\%) e com idade entre 20 e 29 anos (46,5\%). Pertenciam a famílias compostas por entre 3 e 5 pessoas (61\%), com renda familiar entre 1,1 e 3 salários mínimos $(51,4 \%)$. A maioria dos discentes respondentes não trabalhava $(59,2 \%)$ e quando o fazia, o mais frequente era nos turnos manhã e tarde simultaneamente $(28,2 \%)$.

Pela Tabela 2, observou-se também que a maioria destes respondentes pertencia ao curso de Matemática Licenciatura (68,3\%), encontrando-se em posição padrão no curso (61,3\%), embora tivessem poucas disciplinas cursadas e concluídas: o mais frequente foi de até 10 disciplinas (52\%). Além disso, a maioria dos entrevistados não participava de atividades extracurriculares (60,6\%), não possuía bolsa e nem auxílio financeiro da instituição (61,3\%).

Tabela 2 - Características acadêmicas dos discentes respondentes

\begin{tabular}{llcc}
\hline \multicolumn{1}{c}{ Variáveis } & \multicolumn{1}{c}{ Níveis } & $f$ & $\%$ \\
\hline Curso & Matemática Aplicada & 45 & 31,7 \\
& Matemática Licenciatura & 97 & 68,3 \\
\hline Padrão no curso & Sim & 87 & 61,3 \\
& Não & 54 & 38,0 \\
& NI & 1 & 0,7 \\
\hline Disciplinas cursadas e concluídas & Até 10 & 74 & 52,0 \\
& Entre 11 e 22 & 26 & 18,3 \\
& Entre 23 e 35 & 26 & 18,3 \\
& Mais que 35 & 4 & 3,0 \\
& NI & 12 & 8,4 \\
\hline Participação em atividades extraclasse & Sim & 56 & 39,4 \\
& Não & 86 & 60,6 \\
\hline Possui bolsa/ auxílio financeiro & Sim & 55 & 38,7 \\
& Não & 87 & 61,3 \\
\hline
\end{tabular}

Fonte: levantamento de dados.

Obs: $f$ representa frequência de ocorrência; NI representa não informou.

Uma análise exploratória dos dados obtidos para a importância do item encontrou evidências de que os dados não apresentavam distribuição normal e que havia valores fora do padrão para todos os itens, além de assimetria acentuada, conforme evidenciado na Figura 1.

Também é possível constatar que poucos respondentes atribuíram pontuação inferior a 20 para a importância de algum item. Estas pontuações variaram entre 9 e 100, fornecendo importâncias médias por item que variaram entre 81,88 e 96,21 e medianas que variaram entre 90 e 100, indicando que a tendência central destas distribuições foi elevada, o que sugere que todos os itens são importantes para a satisfação. Em relação à variabilidade, a amplitude total por item variou entre 50 e 100, enquanto que o desvio padrão variou entre 10,06 e 24,23 , o que sugere uma variabilidade não muito elevada.

A análise inicial das propriedades dos dados sugeriu que dois itens que se referiam a características pessoais e sociais (envolvimento pessoal com o curso e participação em eventos sociais com colegas) deveriam ser eliminados, pois apresentam baixa correlação com os demais.

Os outros resultados da matriz de correlações se apresentaram dentro do esperado, indicando fatorabilidade, o mesmo acontecendo com o determinante desta matriz, com o teste de esfericidade de Bartlett $\left(\chi^{2}=2428,35\right.$; valor $\left.p<0,0001\right)$ e com o coeficiente KaiserMeyer-Olkin (KMO=0,833). 
O critério de Guttman Kaiser, que seleciona os componentes com autovalor superior a 1,0 a partir de uma PAC, identificou a existência de cinco componentes que explicam $68 \%$ da variância total.

Figura 1 - Representação em diagramas de caixas da distribuição das pontuações atribuídas à importância para a satisfação a cada um dos 27 itens

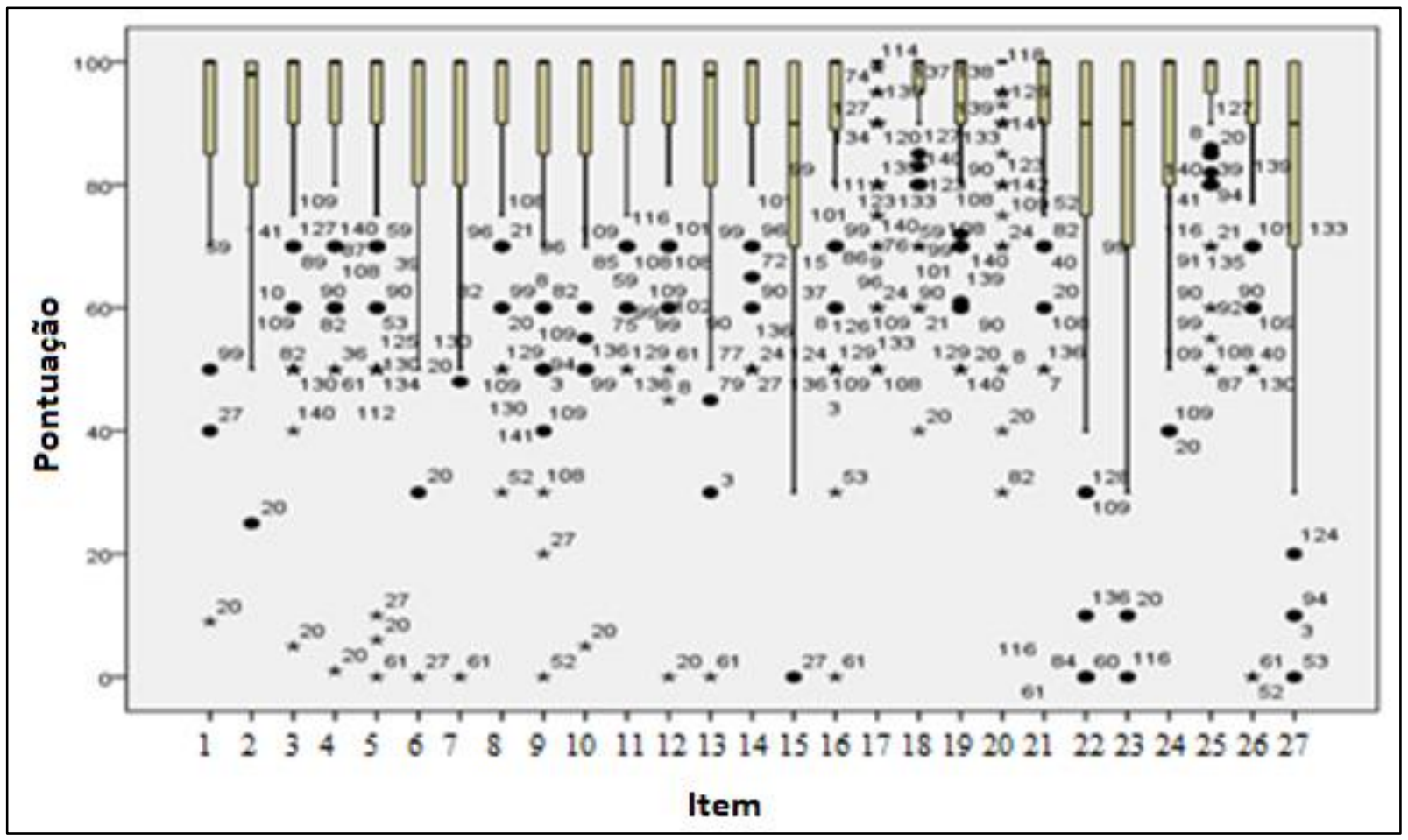

Fonte: análise de dados.

Obs: os números associados aos pontos e asteriscos identificam os respondentes.

A confirmação da quantidade de fatores e respectiva composição foram feitas pela $\mathrm{PAF}$, executada várias vezes com dois métodos de rotação: Obliqua e Varimax, sendo os melhores resultados obtidos com o segundo método. A PAF com rotação Varimax foi executada sete vezes, de modo iterativo. Ao final, mais seis itens foram eliminados, ficando o instrumento com 19 itens em sua última versão, que se distribuíram em 4 fatores explicando $68,98 \%$ da variância total (Tabela 3 ).

Tabela 3 - Autovalor e percentagem explicada da Variância na PAC

\begin{tabular}{cccc}
\hline Componente & Autovalor inicial & \% da variância & \% acumulada \\
\hline 1 & 8,535 & 44,920 & 44,920 \\
2 & 1,897 & 9,985 & 54,905 \\
3 & 1,611 & 8,479 & 63,384 \\
4 & 1,063 & 5,596 & 68,980 \\
5 & 0,837 & 4,405 & 73,385 \\
\hline
\end{tabular}

Fonte: análise estatística.

Obs: Método de extração - Eixos Principais.

Pelas características dos itens de cada agrupamento, eles foram denominados de "Recursos materiais e humanos", "Professor", "Metodologia" e "Disciplinas".

Chama-se a atenção para a importância do primeiro fator que, sozinho, explica 44,92\% da variância. Este, apresentado na Tabela 4, denominado de "Recursos materiais e humanos", 
é formado por dez itens, caracterizados por serviços oferecidos pela instituição. O coeficiente de Cronbach indicou boa confiabilidade, tendo em vista que assumiu o valor de 0,912 . Seus itens apresentaram cargas fatoriais de pelo menos 0,512, o que também é satisfatório. As comunalidades dos itens, definida pela proporção da variância comum presente na variável, variaram entre 0,573 e 0,801, enquanto que a correlação de cada item com o total apresentou um valor mínimo de 0,607 e máximo de 0,767, indicando que os itens estão bastante relacionados com a pontuação total.

Dos dez itens deste fator, oito também foram considerados por Schleich, Polydoro e Santos (2006), embora tenham sido enquadrados em fator considerado menos importante. Destes, o item (1), (2), (3), (4) e (9) foram considerados apenas por Schleich, Polydoro e Santos (2006), os itens (6) foi considerado também por Soares, Vasconcelos e Almeida (2002), enquanto o item (10) foi também considerados por Cunha, Gomes e Beck (2016). O item (5) foi considerado nos três instrumentos. Os itens (7) e (8) foram considerados apenas por Cunha, Gomes e Beck (2016). Chama-se a atenção para o fato de que os itens (9) e (10) aparecem também no fator subsequente, caracterizando-se como itens complexos.

Tabela 4 - Informações sobre o Fator 1: recursos materiais e humanos

\begin{tabular}{|c|c|c|c|c|}
\hline Item & $\begin{array}{l}\text { Carga } \\
\text { fatorial }\end{array}$ & $h^{2}$ & $r_{i t}$ & Descrição \\
\hline 1 & 0,802 & 0,750 & 0,761 & Infraestrutura física da Instituição. \\
\hline 2 & 0,707 & 0,621 & 0,657 & Infraestrutura física das salas de aula. \\
\hline 3 & 0,606 & 0,573 & 0,629 & Segurança oferecida pela Instituição. \\
\hline 4 & 0,738 & 0,707 & 0,767 & Limpeza dos ambientes. \\
\hline 5 & 0,642 & 0,627 & 0,631 & $\begin{array}{l}\text { Informações oferecidas pelos funcionários das } \\
\text { secretarias da Instituição. }\end{array}$ \\
\hline 6 & 0,512 & 0,626 & 0,607 & $\begin{array}{l}\text { Recursos e equipamentos audiovisuais } \\
\text { disponíveis na Instituição. }\end{array}$ \\
\hline 7 & 0,656 & 0,718 & 0,754 & $\begin{array}{l}\text { Concordância das referências bibliográficas } \\
\text { com os conteúdos ministrados nas disciplinas. }\end{array}$ \\
\hline 8 & 0,558 & 0,801 & 0,729 & $\begin{array}{l}\text { Adequação entre atividades e conteúdos } \\
\text { desenvolvidos nas disciplinas. }\end{array}$ \\
\hline 9 & 0,567 & 0,751 & 0,716 & Comprometimento com o ensino. \\
\hline 10 & 0,561 & 0,628 & 0,660 & Qualificação profissional dos professores. \\
\hline
\end{tabular}

Fonte: análise estatística.

Obs: $h^{2}$ representa comunalidade e $r_{i t}$, a correlação de cada item com o total.

A Tabela 5 ilustra o segundo fator, formado por cinco itens e denominado de professor, reunindo itens que representam características do professor em sala de aula. $O$ fator explicou 9,9\% da variância e apresentou um coeficiente de Cronbach igual a 0,861, além de itens com carga fatorial que variam entre 0,473 e 0,783, o que é bastante satisfatório. 0 menor valor de comunalidade foi 0,515 e o maior, 0,751 , enquanto a correlação de cada item com o total variou de 0,586 a 0,764. Os resultados destas estatísticas também são satisfatórios.

Tabela 5 - Informações sobre o Fator 2: professor

\begin{tabular}{ccccl}
\hline Item & Carga fatorial & $\mathrm{h}^{2}$ & $\mathrm{r}_{\mathrm{it}}$ & \multicolumn{1}{c}{ Descrição } \\
\hline 11 & 0,783 & 0,651 & 0,714 & $\begin{array}{l}\text { Clareza por parte dos professores na apresentação } \\
\text { dos conteúdos. }\end{array}$ \\
9 & 0,597 & 0,751 & 0,764 & $\begin{array}{l}\text { Comprometimento com o ensino. }\end{array}$
\end{tabular}




\begin{tabular}{|c|c|c|c|c|}
\hline 12 & 0,696 & 0,658 & 0,756 & $\begin{array}{l}\text { Relação entre a teoria e a prática profissional durante } \\
\text { as aulas. }\end{array}$ \\
\hline 10 & 0,473 & 0,628 & 0,594 & Qualificação profissional dos professores. \\
\hline 13 & 0,532 & 0,515 & 0,586 & Coerência nas avaliações das disciplinas \\
\hline
\end{tabular}

Fonte: análise estatística.

Obs: $h^{2}$ representa comunalidade e $r_{i t}$, a correlação de cada item com o total.

Este segundo fator apresentou três dos cinco itens semelhantes aos propostos por Cunha, Gomes e Beck (2016) que consideraram dois deles em um dos seus fatores mais importantes: envolvimento dos professores. São eles os itens (12) e (10), sendo o último também abordado por Schleich, Polydoro e Santos (2006), que também considerou o item (9). Já o item (13) foi citado nos três estudos, enquanto o item (11) não foi abordado desta forma em nenhum dos estudos.

O terceiro fator (Tabela 6), explica $8,479 \%$ da variância total e é denominado Metodologia, pois reúne recursos pedagógicos oferecidos pelo professor e pela instituição, com a finalidade de auxiliar o processo de ensino-aprendizagem. Composto por apenas três itens, as comunalidades obtidas variam de 0,62 a 0,652, as cargas fatoriais são superiores a 0,578 , o coeficiente de Cronbach foi de 0,770 e a correlação de cada item com o total variou entre 0,60 e 0,727. Os resultados destas estatísticas são satisfatórios.

Tabela 6 - Informações dobre o Fator 3: metodologia

\begin{tabular}{ccccl}
\hline Item & $\begin{array}{c}\text { Carga } \\
\text { fatorial }\end{array}$ & $h^{2}$ & $r_{i t}$ & \multicolumn{1}{c}{ Descrição } \\
\hline 14 & 0,578 & 0,652 & 0,607 & $\begin{array}{l}\text { Equipamentos e softwares oferecidos nos } \\
\text { laboratórios de informática. }\end{array}$ \\
15 & 0,691 & 0,620 & 0,600 & $\begin{array}{l}\text { Recursos pedagógicos. } \\
16\end{array}$ \\
\hline
\end{tabular}

Fonte: análise estatística.

Obs: $h^{2}$ representa comunalidade e $r_{i t}$, a correlação de cada item com o total.

O estudo de Schleich, Polydoro e Santos (2006) utilizou o item (16), que ficou em seu fator mais importante, e (14), locado em seu fator menos importante. Este primeiro também foi considerado por Cunha, Gomes e Beck (2016) no seu fator mais importante, que também contribuíram com o fator (15).

O quarto e último fator recebeu o nome de disciplinas e está ilustrado na Tabela 7, expleicando 5,596\% da variância total. Esse fator também é formado por apenas três itens, seu coeficiente de Cronbach foi de 0,744 e possui comunalidades que variam entre 0,529 e 0,623 . Suas cargas fatoriais são superiores a 0,553 e a correlação item-total apresenta um valor máximo de 0,679 e mínimo de 0,546. Os resultados destas estatísticas são satisfatórios.

Tabela 7 - Matriz Fatorial do Fator 4: disciplinas

\begin{tabular}{ccccl}
\hline Item & $\begin{array}{c}\text { Carga } \\
\text { fatorial }\end{array}$ & $h^{2}$ & $r_{i t}$ & \multicolumn{1}{c}{ Descrição } \\
\hline 17 & 0,553 & 0,529 & 0,546 & $\begin{array}{l}\text { Ementa das disciplinas adequada a sua carga } \\
\text { horária }\end{array}$ \\
18 & 0,674 & 0,550 & 0,645 & $\begin{array}{l}\text { Interdisciplinaridade entre as disciplinas do } \\
\text { curso. } \\
\text { Incentivo a debates em sala de aula. }\end{array}$ \\
\hline
\end{tabular}

Fonte: análise estatística. Obs: $h^{2}$ representa comunalidade e $r_{i t}$, a correlação de cada item com o total. 
Todos os itens deste último fator foram considerados apenas no trabalho de Cunha, Gomes e Beck (2016), embora em diferentes dimensões. Para estes autores, (19) ficou no fator interação estudante-professor, o segundo fator mais importante do instrumento, enquanto o item (17) em demandas do curso. Já o item (18) ficou no fator organização do curso, o fator menos importante destes três.

Depois de identificada a composição dos quatro fatores, constatou-se que o fator mais importante do instrumento, que envolve recursos humanos e materiais, havia ficado com uma quantidade maior de itens, sugerindo a possibilidade de decomposição. Além disso, uma análise semântica destes itens sugeriu dois grupos: um deles envolvendo aspectos administrativos e o outro, aspectos pedagógicos. Entretanto, uma PAF aplicada a estes 10 itens não foi favorável a sua decomposição, confirmando a existência de apenas um fator.

Durante a execução desta análise, o instrumento se reduziu a 19 itens. Os seis itens eliminados na PAF são bastante diversificados e se relacionam a características da instituição, do curso e dos professores. São eles: acervo disponível na biblioteca, programas e serviços de apoio financeiro ao estudante oferecidos pela Instituição, grade curricular, atividades extracurriculares diversificadas, cumprimento dos conteúdos previstos nas ementas das disciplinas e receptividade dos professores em relação a novas ideias e diferentes pontos de vista.

Os resultados obtidos nesta análise evidenciam a subjetividade do constructo mensurado e sua sensibilidade aos valores dos indivíduos, bem como ao contexto em que estão inseridos, pois os discentes interpretam a sua atmosfera acadêmica de maneira diferente.

Na amostra investigada, o fator "Recursos humanos e materiais", considerado como o mais importante neste estudo, com predominância de itens relacionados à instituição, foi considerado o segundo mais importante entre o três fatores de Soares, Vasconcelos e Almeida (2002) e o menos importante entre os três fatores de Schleich, Polydoro e Santos (2006). Ainda, no instrumento de Cunha, Gomes e Beck (2016) a maior parte destes itens não foi considerada.

$\mathrm{O}$ segundo e o terceiro fator identificados neste estudo dizem respeito à postura do professor e sua metodologia, contendo itens que nos instrumentos de Soares, Vasconcelos e Almeida (2002), Schleich, Polydoro e Santos (2006) e Cunha, Gomes e Beck (2016) compuseram o fator mais importante. Diferentemente do esperado, o papel do professor no processo de ensino-aprendizagem, apontado por diversos autores como de extrema importância, parece não ter sido muito valorizado pelos discentes respondentes.

O quarto e último fator diz respeito à estruturação dos cursos em relação às disciplinas. Nos instrumentos analisados não houve um fator com esta especificidade, mas houve itens relativos a ementas, currículo, interdisciplinaridade e organização do curso que não seguiram um padrão: ficaram entre os fatores mais importantes em Soares, Vasconcelos e Almeida (2002), no segundo fator mais importante de Schleich, Polydoro e Santos (2006) e entre os menos importantes para Cunha, Gomes e Beck (2016).

Chamou a atenção que dois itens que estavam nos instrumentos de Soares, Vasconcelos e Almeida (2002), de Schleich, Polydoro e Santos (2006) e de Cunha, Gomes e Beck (2016), relativos ao atendimento fornecido pelos funcionários da secretaria, o que facilita o dia a dia dos discentes, e à avaliação realizada nas disciplinas pelos professores, um feedback da aprendizagem para os discentes, continuaram neste instrumento que está sendo proposto, sugerindo alguma similaridade com instrumentos que medem a satisfação do 
consumidor de uma maneira geral, que dão muita importância a aspectos relacionados ao atendimento ao cliente, representado neste estudos pelos discentes. Esses achados parecem concordar com Ferreira (2005) que afirma que o contato pessoal é um dos fatores que mais influencia a avaliação do discente quanto à qualidade dos serviços oferecidos pela instituição de ensino.

Estudiosos na área de gestão criaram modelos para representar a satisfação identificando antecedentes (imagem da instituição, expectativa do consumidor, qualidade percebida e valor percebido) e consequentes (reclamações e lealdade). Nestes modelos, a imagem da instituição interfere nas expectativas e, consequentemente, na satisfação. Silva e Giraldi (2010), usando um destes modelos, identificaram que o atendimento é uma das dimensões da imagem da instituição que mais interfere na satisfação do consumidor, o que parece ter acontecido no presente estudo e nos anteriores.

\section{Considerações finais}

O presente estudo complementa o estudo apresentado em Dutra, Ávila e Mattos (2017), mostrando a validação de construto de um instrumento construído para mensurar a satisfação de discentes de cursos de graduação em Matemática. O instrumento encontrou fatores ou dimensões diferentes dos estudos que o fundamentaram, não só em composição como em importância, o que evidencia a necessidade de uma adaptação permanente dos instrumentos desenvolvidos com esta finalidade. A subjetividade do constructo a ser mensurado e sua sensibilidade aos valores dos indivíduos e ao contexto em que estão inseridos reforçam esta necessidade.

Os achados indicam que, na população investigada, aspectos mais relacionados à infraestrutura oferecida pela instituição, tanto em relação à parte material como humana, e que pertencem ao fator mais importante, tais como: infraestrutura física, recursos áudio visuais, limpeza e segurança, foram considerados mais importantes que aspectos mais ligados à aprendizagem propriamente dita, tais como: recursos pedagógicos, interdisciplinaridade, atendimento extraclasse e ementa das disciplinas. Entretanto, comprometimento com o ensino por parte dos professores e a qualificação profissional dos professores foram itens bastante valorizados, evidenciando a sua importância na satisfação dos discentes e, consequentemente, sua influência no sucesso do processo de ensino-aprendizagem.

Salienta-se que este instrumento passou por uma validação de conteúdo, descrita em Dutra, Ávila e Mattos (2017), sendo identificado um conjunto de itens relevantes para os diferentes domínios que compõe a satisfação discente, por uma validação de construto, sendo identificadas variáveis latentes e suas composições, e por uma análise de confiabilidade. Os resultados encontrados foram satisfatórios, mas sob o ponto de vista técnico, a realização de uma Análise Fatorial Confirmatória é conveniente.

Além disso, as características do constructo mensurado sugerem a avaliação da possibilidade de utilização da métrica fuzzy, especialmente indicada para a mensuração de variáveis complexas, imprecisas e vagas. De acordo com Mattos et al. (2016), a utilização desta métrica neste contexto pode ser adequada porque avaliações sobre o comportamento humano podem obter melhores resultados se forem feitas com menor rigor e precisão, apresentando uma estruturação mais tolerante e semelhante a forma de pensar e tirar conclusões dos indivíduos. 


\section{Agradecimentos}

Agradecemos a CAPES pelo auxílio financeiro na forma de bolsa de mestrado Demanda Social, à Universidade Federal de Rio Grande e ao Programa Pós-Graduação em de Modelagem Computacional desta mesma instituição.

\section{Referências}

BONICI, Rosângela Maura Correa, ARAÚJO JUNIOR, Carlos Fernando. Medindo a satisfação dos estudantes em relação a disciplina on-line de Probabilidade e Estatística. In: Proceedings of 17ㅇ. Congresso Internacional de Educação a Distância; 2011 Aug 30-02; Manaus. p. 1-10. Available from: http://www.abed.org.br/ congresso2011/cd/190.pdf. Acesso em: 12 já n. 2017

COCK, Dagfinn; HALVARI, Hallgeir. Motivation, performance and satisfaction at school. In: EFKLIDES, Anastasia; KUHL, Julius; SORRENTINO, Richard M. Trends and prospects in motivation research. $p$. 65-84, 2001. doi: 10.1007/0-306-47676-2.

CUNHA, Paulo Roberto da; GOMES, Giancarlo; BECK, Franciele. Satisfação dos Estudantes do Curso de Ciências Contábeis: Estudo em Universidades Públicas de Santa Catarina. Contabilidade Vista \& Revista, v. 27, n. 1, p. 42-62, 2016.

CRUZ, Jaqueline Valério da; SILVA, Paulo Vilhena da. Jogos e objetos matemáticos como recurso pedagógico: terapia wittgensteiniana dos conceitos psicológicos. Boletim online de Educação Matemática, v.7, n.14, p.43-59, 2019.

DAVIS J. Charlene; SWANSON, Scott T. Navigating satisfactory and dissatisfactory classroom incidents. Journal of Education for Business, v.76, n.5, p.245-250, 2001. doi: 10.1080/08832320109599643.

DUTRA, Vanussa Braga Rezende, ÁVILA, Sarah Hartman, MATTOS, Viviane Leite Dias de. Validação de um instrumento de avaliação da satisfação dos discentes de cursos de graduação em Matemática. Scientia Plena, v.13, n.4: p. 1-19, 2017. doi: 10.14808/sci.plena.2017.049911.

EL-HILALI, Nabil; AL-JABER, Sara; HUSSEIN, Lina. Student's satisfaction and achievement and absorption capacity in Higher education. Procedia - Social and Behavioural Sciences, v.177, p. 420427, 2015. doi: 10.1016/i.sbspro.2015.02.384.

FERREIRA, Almiro. Uma Análise das Dimensões da Qualidade de Serviços em Educação Superior para Estabelecimento de Cursos de Pós-Graduação [dissertação]. Porto Alegre: Mestrado em Engenharia: Gerência de Serviços/Universidade Federal do Rio Grande do Sul; 2005, 142p.

HAIR, Joseph; BABIN, Barry; ANDERSON, Ralph; BLACK, William. Multivariate data analysis. 6‥ Ed. Prentice Hall, 2009.

INEP. Instituto Nacional de Estudos e Pesquisas Educacionais Anísio Teixeira. Censo da Educação Superior: notas estatísticas, 2018.

LODI, Emesto; BOERCHI< Diego; MAGNANO, Paola; PATRIZI, Patrizia. High-School Satisfactiona Scale (H-Sat Scale): evaluation of contextual satisfaction in relation to High-school students' life satisfaction. Behavioral Sciences, v.9, n.12, 2019. doi: 10.3390/bs9120125. 
MATTOS, Viviane Leite Dias de, AVILA, Sarah Hartmann, FIGUEIREDO, Vera Lúcia Marques de. Um instrumento para medir a satisfação dos passageiros de um sistema de transporte público. GEPROS. Gestão da Produção, Operações e Sistemas, v.12, n.1, p.63-81, 2017. doi: 10.15675/gepros.v12i1.1599.

Michaelis. Moderno dicionário da língua portuguesa. Editora: Melhoramentos, 2009.

OLIVEIRA, Marcelo de Sousa. Uma reflexão sobre a ideia de superação do ensino tradicional na educação matemática: a dicotomia entre a abordagem clássica e abordagens inovadoras em foco. Boletim online de Educação Matemática, v.7, n.14, p.79-93, 2019.

PASQUALI, Luis. Análise Fatorial para pesquisadores. 1 ed. Brasília: Editora LabPAM, 2005.

PARASURAMAN, A.; ZEITHAML, Valarie A.; BERRY, Leonard L. A conceptual model of service quality and its implications for future research. Journal of Marketing, v.49, n.4, p.41-50, 1985. doi: $10.1177 / 002224298504900403$.

PASWAN, Audhesh J.; YOUNG, Joyce A. Student evaluation of instructor: a nomological investigation using structural equation modeling. Journal of Marketing Education, v.24, n.3, p.193-202, 2002. doi: 10.1177/0273475302238042.

RODRIGUEZ, Barbara Denicol do Amaral; MENEGHETTI, Cinthya Maria Schneider; POFFAL, Cristiana Andrade. Estudo do perfil dos alunos do curso de Matemática Aplicada-Bacharelado: entendendo as razões para o baixo rendimento dos acadêmicos. Ciência e Natura, v.37, n.1, p.152-162, 2015. doi:10.5902/2179460X14785.

ROZAL, Edilene Farias; ESPÌRITO SANTO, Adilson Oliveira; CHAVES, Isaura Albuquerque. O que se aprende com imagens matemáticas? Uma experiência na Educação de Jovens e Adultos. Boletim online de Educação Matemática, v.3, n.5, p.19-50, 2015.

SCHLEICH, Ana Lúcia Righi; POLYDORO, Soely Apareccida Jorge; SANTOS, Acácia Aparecida Angeli dos. Escala de satisfação com a experiência acadêmica de estudantes do Ensino Superior. Avaliação Psicológica, v.5, n.1, p.11-20, 2006.

SILVA Tarsis Souza; GIRALDI, Janaina de Moura Engracia. A Influência das dimensões da imagem de loja varejista na satisfação do cliente: um estudo em uma loja de calçados. Brazilian Business Review, v.7, n.2, p.64-83, 2010.

SOARES, Ana Paula C.; VASCONCELOS, Rosa M.; ALMEIDA, Leandro S. Adaptação e Satisfação na Universidade: apresentação e validação do Questionário de Satisfação Acadêmica. Contextos e dinâmica da vida acadêmica, p.153-165, 2002.

SOUZA, Saulo Aparecido de; REINERT, José Nilson. Avaliação de um curso de ensino superior através da satisfação/insatisfação discente. Revista da Avaliação da Educação Superior, v.15, n.1, p.159-176, 2010.

SULTAN, Parves; WONG, Ho Yin. Antecedents and consequences of service quality in a higher education context: a qualitative research approach. Quality Assurance in Education, v.21, n.1, p.7095, 2013. doi: 10.1108/09684881311293070. 
SU, Alexandre Fun Ghi; SAMPAIO, Mauro. Adaptação cultural e validação dos construtos: serviço logístico, satisfação e lealdade. Gestão da produção, v.20, n.3, p.587-601, 2013.

VIEIRA, Kelmara Mendes; MILACH, Felipe Tavares; HUPPES, Daniela. Equações estruturais aplicadas à satisfação dos alunos: um estudo no curso de Ciências Contábeis da Universidade Federal de Santa Maria. Revista Contabilidade \& Finanças, v.19, n.48, p.65-76, 2008. 